Published in final edited form as:

J Genet Couns. 2017 February ; 26(1): 79-92. doi:10.1007/s10897-016-9981-6.

\title{
Adherence to Recommended Risk Management Among Unaffected Women with a BRCA Mutation
}

\author{
Adam H. Buchanan ${ }^{1}$, Corrine I. Voils ${ }^{2,3}$, Joellen M. Schildkraut ${ }^{4}$, Catherine Fine ${ }^{5}$, Nora K. \\ Horick $^{6}$, P. Kelly Marcom ${ }^{3,4}$, Kristi Wiggins ${ }^{7}$, and Celette Sugg Skinner ${ }^{8}$ \\ ${ }^{1}$ Genomic Medicine Institute, Geisinger Health System, Danville, PA, USA \\ ${ }^{2}$ Center for Health Services Research in Primary Care, Durham VA Medical Center, Durham, NC, \\ USA \\ ${ }^{3}$ Department of Medicine, Duke University Medical Center, Durham, NC, USA \\ ${ }^{4}$ Duke Cancer Institute, Duke University Medical Center, Durham, NC, USA \\ ${ }^{5}$ Department of Genetics, UNC Lineberger Comprehensive Cancer Center, Chapel Hill, NC, USA \\ ${ }^{6}$ Massachusetts General Hospital Biostatistics Center, Boston, MA, USA \\ ${ }^{7}$ Division of Cellular Therapy, Duke University Medical Center, Durham, NC, USA \\ ${ }^{8}$ Department of Clinical Sciences and Harold C Simmons Cancer Center, University of Texas - \\ Southwestern, Dallas, TX, USA
}

\begin{abstract}
Corresponding author: Adam H Buchanan, M.C. 26-20, 100 N. Academy Ave., Danville, PA 17822, ahbuchanan@ geisinger.edu, +1-570-214-4747 (phone), +1-570-214-7342 (fax).

Portions of this work have been presented at:

1. The 32nd Annual Education Conference of the National Society of Genetic Counselors, October 2013, Anaheim, CA.

2. BRCA: Twenty Years of Advances - The Fifth International Symposium on Hereditary Breast and Ovarian Cancer, April 2014, Montreal, QC.
\end{abstract}

Compliance with Ethical Standards

The study described here was funded by R03CA157212. Portions of the salaries of Mr. Buchanan and Drs. Voils, Schildkraut and Skinner were covered under this grant. This article was supported with resources and facilities of the Veterans Affairs Medical Center in Durham, NC. It was further supported by UL1 RR024128-01 from the National Center for Research Resources (NCRR), a component of the National Institutes of Health (NIH), and NIH Roadmap for Medical Research. Its contents are solely the responsibility of the authors and do not necessarily represent the official view of NCRR or NIH.

Mr. Buchanan's work has been funded by the NIH and Susan G. Komen for the Cure. Dr. Voils. work has been funded by the Department of Veterans Affairs and the NIH. Dr. Schildkraut's work has been funded by the NIH. Dr. Marcom's work has been funded by the NIH and Department of Defense. Dr. Skinner's work has been funded by the NCI and the Cancer Prevention Research Institute of Texas. The authors declare that these relationships do not present conflicts of interest. Ms. Fine, Ms. Horick and Ms. Wiggins declare no conflicts of interest.

Study data were collected and managed using REDCap electronic data capture tools hosted at Massachusetts General Hospital. REDCap (Research Electronic Data Capture) is a secure, web-based application designed to support data capture for research studies, providing 1) an intuitive interface for validated data entry; 2) audit trails for tracking data manipulation and export procedures; 3 ) automated export procedures for seamless data downloads to common statistical packages; and 4) procedures for importing data from external sources.

All procedures followed were in accordance with the ethical standards of the responsible committee on human experimentation (institutional and national) and with the Helsinki Declaration of 1975, as revised in 2000. Informed consent was obtained from all patients for being included in the study.

No animal studies were carried out by the authors for this article. 
Identifying unaffected women with a $B R C A$ mutation can have a significant individual and population health impact on morbidity and mortality if these women adhere to guidelines for managing cancer risk. But, little is known about whether such women are adherent to current guidelines. We conducted telephone surveys of 97 unaffected BRCA mutation carriers who had genetic counseling at least one year prior to the survey to assess adherence to current guidelines, factors associated with adherence, and common reasons for performing and not performing recommended risk management. More than half of participants reported being adherent with current risk management recommendations for breast cancer $(69 \%, \mathrm{n}=67)$, ovarian cancer $(82 \%$, $\mathrm{n}=74)$ and both cancers $(66 \%, \mathrm{n}=64)$. Older age $(\mathrm{OR}=10.53, \mathrm{p}=0.001)$, white race $(\mathrm{OR}=8.93$, $\mathrm{p}=0.019)$, higher breast cancer genetics knowledge $(\mathrm{OR}=1.67, \mathrm{p}=0.030)$, higher cancer-specific distress $(\mathrm{OR}=1.07, \mathrm{p}=0.002)$ and higher physical functioning $(\mathrm{OR}=1.09, \mathrm{p}=0.009)$ were significantly associated with adherence to recommended risk management for both cancers. Responses to open-ended questions about reasons for performing and not performing risk management behaviors indicated that participants recognized the clinical utility of these behaviors. Younger individuals and those with lower physical functioning may require targeted interventions to improve adherence, perhaps in the setting of long-term follow-up at a multi-disciplinary hereditary cancer clinic.

\section{Keywords}

BRCA1 gene; BRCA2 gene; genetic counseling; breast cancer; ovarian cancer

\section{INTRODUCTION}

Hereditary Breast and Ovarian Cancer (HBOC) syndrome, caused by inherited mutations in $B R C A 1$ and $B R C A 2$ genes, poses a substantial health burden on an individual and population basis, with significantly increased lifetime risks of breast and ovarian cancer (Chen \& Parmigiani, 2007) and an estimated population prevalence of 1:400 (Petrucelli, Daly, \& Feldman, 2013). Yet, this health burden can be greatly mitigated through prophylactic surgery and surveillance, which are associated with significant reduction in morbidity and mortality among women with HBOC syndrome (A. Finch et al., 2006; A. P. Finch et al., 2014; Kurian, Sigal, \& Plevritis, 2010; Rebbeck et al., 2004; Rebbeck, Kauff, \& Domchek, 2009; Warner et al., 2011).

Therefore, the Centers for Disease Control and Prevention's Office of Public Health Genomics ranks HBOC syndrome as having top-tier evidence (Khoury, Coates, \& Evans, 2010) for integrating genomic information into public health practice for reducing morbidity and mortality (CDC, 2014). Since 2000, the National Comprehensive Cancer Network (NCCN) expert consensus guidelines have specified the timing and frequency of prophylactic surgery and surveillance for individuals with HBOC syndrome (NCCN, 2015). There are compelling public health and clinical reasons for determining whether those with HBOC syndrome are adherent to these guidelines. As Schwartz et al. (2003) argue, "[f]or $B R C A 1 / 2$ testing to reach its potential to reduce cancer mortality and morbidity, receipt of a positive test result must be followed by the adoption of appropriate prevention or surveillance behaviors" (Schwartz et al., 2003). 
Standard-of-care cancer genetic counseling, which includes pre- and post-test discussion of risk management options, should include encouragement for adoption of recommended behaviors (American Society of Clinical Oncology, 2003; Berliner, Fay, \& Practice Issues Subcommittee of the National Society of Genetic Counselors' Familial Cancer Risk Counseling Special Interest, 2007; Robson et al., 2009; Trepanier et al., 2004). Prevention and early detection may have the biggest impact on morbidity and mortality for unaffected mutation carriers (i.e., those without cancer), but we know little about risk management among this at-risk group.

Available data suggest wide variation in uptake of prophylactic surgery, with rates ranging from 18\% to 74\% (Bradbury et al., 2008; Garcia et al., 2014; H. Meijers-Heijboer et al., 2003; Metcalfe et al., 2008; Schmeler et al., 2006; Sidon et al., 2012), and sub-optimal rates of breast and ovarian cancer surveillance (Botkin et al., 2003; Garcia et al., 2014; Kinney et al., 2006; Lerman et al., 2000; Metcalfe et al., 2008; Peshkin et al., 2002; Phillips et al., 2006; Tinley et al., 2004; Uyei et al., 2006). Yet, this literature is often limited by short follow-up time (Claes et al., 2005; Kinney et al., 2006; Lerman et al., 2000; Lodder et al., 2002; Peshkin et al., 2002; Schwartz et al., 2003), small sample size (Botkin et al., 2003; Bradbury et al., 2008; Claes et al., 2005; Kinney et al., 2006; Peshkin et al., 2002; Tinley et al., 2004; Uyei et al., 2006), highly selected samples with access to no-cost genetic counseling and risk management (Botkin et al., 2003; Bradbury et al., 2008; Claes et al., 2005; Lerman et al., 2000; E. J. Meijers-Heijboer et al., 2000; Peshkin et al., 2002), and mixed samples of affected and unaffected mutation carriers (Scheuer et al., 2002).

Another limitation of previous research is that current adherence has not been assessed (Botkin et al., 2003; Garcia et al., 2014). Reports typically focus on whether a behavior has ever been performed rather than whether it has been performed within the recommended time period (Metcalfe et al., 2008). Assessing adherence to current risk management recommendations is important because risk management guidelines for carriers have evolved as new evidence has emerged to support the effectiveness of surveillance and prophylactic surgery (Burke et al., 1997; NCCN, 2015). Hence, it is possible that carriers who would have been considered adherent years ago are no longer adherent. Indeed, they may not even be aware of current guidelines.

We conducted telephone interviews among 97 unaffected $B R C A$ mutation carriers to address three research questions: 1) To what extent are unaffected $B R C A$ mutation carriers adherent to current NCCN risk management guidelines? 2) Which participant characteristics and beliefs are associated with adherence and non-adherence to these guidelines? and 3) What are common reasons for performing and not performing recommended breast and ovarian cancer risk management?

Knowing why unaffected carriers are or are not adherent to recommended risk management can facilitate development of interventions to improve adherence and therefore achieve the public health benefits of identifying $B R C A$ mutation carriers. 


\section{METHODS}

\section{Design}

We used a cross-sectional, single-group design to assess adherence to current risk management recommendations and reasons for adherence and non-adherence among BRCA1/2 mutation carriers who had not been diagnosed with breast or ovarian cancer at the time of the interview. The study was approved by institutional review boards of Duke University Medical Center and The University of North Carolina - Chapel Hill.

\section{Theoretical Framework}

The Health Belief Model (HBM) (C.S. Skinner, Tiro, \& Champion, 2015) and literature review informed selection of variables measured via the survey. As shown in Figure 1, the HBM can be readily applied to determining which factors are associated with prophylactic surgery or surveillance in unaffected mutation carriers. Modifying factors such as age, cancer worry and knowledge can influence beliefs about cancer and performance of risk management (e.g., perceived cancer risk, perceived self-efficacy to perform behaviors). The HBM posits that these beliefs and relevant cues to action (e.g., physician recommendation) affect likelihood of adherence. Although HBM variables have been associated with risk management behaviors (Bradbury et al., 2008; Claes et al., 2005; Hughes et al., 2002; Lerman et al., 2000; Schwartz et al., 2003; Tinley et al., 2004; Uyei et al., 2006), no previous studies have assessed all of these variables. Nor have previous studies been designed to suggest variables to target in an intervention.

\section{Sample}

Eligible women were $B R C A$ mutation carriers age 25 or older, with no personal history of breast or ovarian cancer, who had standard-of-care pre- and post-test cancer genetic counseling at Duke Cancer Institute or The University of North Carolina's Cancer Center. These clinics have been active since 1996. Age 25 was the lower age limit of eligibility because NCCN guidelines recommend that $B R C A$ carriers begin imaging for breast cancer surveillance at this age (NCCN, 2015). BRCA carriers who had breast or ovarian cancer were excluded because their risk management is individualized according to a variety of clinical factors beyond the scope of the study to assess. Carriers who received results less than one year ago were excluded because they may not have had sufficient time to engage in recommended risk management behaviors. There was no upper limit for eligibility on time since results disclosure.

\section{Genetic Counseling}

At the Duke and UNC clinics, pre-testing genetic counseling is conducted in-person, with patients in select remote clinics affiliated with Duke and UNC having the option for a telemedicine visit via live videoconferencing beginning in 2008. Patients are given the choice to discuss genetic test results in person or via phone. Patients with positive or uncharacterized variant results who elect to discuss results via phone are encouraged to return in person (or via telemedicine) for a more detailed discussion of the results. implications. Results sessions for individuals with mutations include a discussion of the 
NCCN-recommended risk management behaviors (NCCN, 2015). Genetic counselors at each clinic coordinate short-term follow-up (e.g., referrals to high-risk breast clinic or psychosocial counseling) for patients with a mutation as needed. As is standard of care (Riley et al., 2012), neither clinic performs ongoing coordination of risk management.

\section{Recruitment and Data Collection Procedures}

A genetic counselor at each clinic queried clinic databases for a list of patients who met eligibility criteria and mailed these patients a letter, signed by the clinic director, describing the study and giving a toll-free number to call to opt out of further contact. Three weeks after mailing the letter, Duke and UNC staff members securely uploaded to REDCap ${ }^{\text {TM }}$ (Harris et al., 2009) the names and contact information of those patients who had not opted out. Study staff then attempted to contact these individuals to describe the study and administer the survey to those who gave verbal consent to participate. Computer-assisted telephone interviewing, in which staff entered survey responses electronically in real time, produced survey data with low item non-response and high detail on open-ended questions. Recruitment calls continued until the interviewer exhausted the list of potentially eligible patients. Study recruitment period was July 2012-February 2013.

After completion of all surveys, a nurse practitioner with experience in cancer genetics, but no involvement with either clinic, audited clinic charts to determine which risk management behaviors were discussed by the genetics team during results disclosure session. For each behavior, the auditor determined whether the recommendation recorded in the chart was to "recommend," "consider," or "do not have" the procedure; additional options included "recommendation unclear, "not mentioned," and, for mastectomy/oophorectomy, "not applicable" due to already having already undergone the procedure. The recommended frequency for mammography was also recorded from the chart. A genetic counselor at each clinic queried the clinical databases for additional variables.

\section{Measures}

Prior to survey administration, we pre-tested the survey via cognitive interviewing (Willis, 2005 ) with 16 female, affected $B R C A$ mutation carriers in two iterative rounds of testing to ensure item and response option comprehension and ability to recall information. The final telephone survey assessed performance of each risk management behavior within the recommended time frame. Time since last mammogram and breast MRI were assessed with measures adapted from our previous work (C. Skinner et al., 2005). To determine whether participants had considered ovarian cancer surveillance, we asked whether they had decided to have surveillance, decided not to have surveillance, thought about surveillance but haven't decided, or haven't thought much about surveillance. Performance of risk management behaviors was assessed via self-report rather than medical records review because of acceptable validity for similar screening behaviors (Caplan et al., 2003; King, Rimer, Trock, Balshem, \& Engstrom, 1990; Zapka et al., 1996), and because many of the patients who had genetic counseling and testing in the participating clinics receive ongoing care elsewhere. Open-ended items developed for this study assessed reasons to do and not do a behavior: "What do you see as the main reasons TO [perform risk management behavior]?" and "What do you see as the main reasons NOT to [perform risk management behavior]?" We were 
interested in how participants viewed the risk management behaviors in general, rather than in their personal perceived benefits and barriers, because we thought it would provide a more comprehensive picture of the positive and negative messages they have received on each risk management behavior.

The survey also measured several HBM-based modifying factors, individual beliefs and cues to action that have been associated with risk management behaviors in previous studies (Bradbury et al., 2008; Claes et al., 2005; Lerman et al., 2000; Peshkin et al., 2002; Schmeler et al., 2006; Schwartz et al., 2003; Tinley et al., 2004; Uyei et al., 2006). Patients. report of recommended risk management (i.e., what behaviors were recommended and how often were they recommended, if applicable) was assessed using items from Tinley et al. (Tinley et al., 2004). Perceived breast and ovarian cancer risk were assessed by a single item that uses a 5-point scale to ask women whether they perceive their breast/ovarian cancer risk to be much lower, lower, the same, higher or mugh higher than other women their age (Schwartz et al., 2003). Breast and ovarian cancer worry were each assessed via a three-item measure that asks women how often in the last month they have thought about their chances of developing breast/ovarian cancer and how often these thoughts have affected their daily activities (4-point scale: not at all, sometimes, often, or a lot) (Schwartz et al., 2003). Anxiety and cancer-specific distress were measured via the state subscale of the State-Trait Anxiety Inventory (STAI) (Spielberger, Gorsuch, Lushene, \& al., 1983) and Impact of Events Scale (IES) (Horowitz, Wilner, \& Alvarez, 1979), respectively (4-point scale: not at all, somewhat, moderately so, very much so; and 4-point scale: not at all, rarely, sometimes, often, respectively). Knowledge of breast cancer genetics was measured using a 10-item true-false scale tested by Calzone et al. (Calzone et al., 2005). Physical and mental functioning were assessed via the Short-Form (SF-12) Health Survey (Ware, Kosinski, \& Keller, 1996), which asks participants to rate their physical and mental health and the degree to which their health limits daily physical and social activities. Participants are described hereafter according to whether they scored higher or lower in perceived physical and mental functioning (e.g., lower physical functioning). Communication of results with family members was assessed via a scale developed by Patenaude et al., which asks women to state the number of first- and second-degree relatives who were living at the time of results disclosure and report with which of these relatives they discussed their BRCA results (Patenaude et al., 2006). Demographics and number of relatives with breast or ovarian cancer were assessed with items from our previous work (Buchanan et al., 2009; C. Skinner et al., 2005; C. S. Skinner et al., 2011).

Participants were asked to recall what their genetics team had recommended for each risk management behavior. First, participants were asked whether their genetics team had discussed the behavior. Those who answered ,yes. were asked to select what the genetics team recommended for the behavior using a close-ended item (e.g., "How often did your genetic counselor or geneticist recommended that you have a breast MRI: every 6 months; every year; every 2 years; another interval of time:___; he or she didn't say; he or she recommended that you NOT have a breast MRI; don't remember".) They were also asked to recall risk management recommendations made by other clinicians at any time post results discussion, and were asked via a close-ended item what the recommending clinicians. specialties were (e.g., primary care doctor, gynecologist, oncologist, surgeon). To account 
for participants receiving different recommendations from multiple clinicians, participants were allowed to select multiple management recommendations and clinician specialties for each behavior.

Other variables that could be associated with adherence (age, time from receipt of test results to survey completion, gene with pathogenic variant $-B R C A 1$ or BRCA2) (Bradbury et al., 2008; Lerman et al., 2000; Peshkin et al., 2002; Scheuer et al., 2002; Schmeler et al., 2006; Schwartz et al., 2004; Uyei et al., 2006) were assessed by querying our clinical databases.

\section{Variables and Statistical Analysis}

Adherence to recommended risk management, a dichotomous variable, was calculated separately for each cancer according to 2012 NCCN guidelines, the most recent guidelines at the time of data collection and analysis. Participants were considered to be adherent to breast cancer risk management recommendations if they have had: (a) bilateral mastectomy ever OR (b) mammogram and breast MRI within the last 15 months. NCCN guidelines recommended that women with a $B R C A$ mutation consider ovarian cancer surveillance via CA-125 testing and pelvic ultrasounds, rather than recommending that women perform surveillance (NCCN, 2012). Therefore, participants were considered adherent to ovarian cancer risk management recommendations if they have had: (a) bilateral salpingooophorectomy ever OR (b) had ever considered CA-125 testing and pelvic ultrasound. We included participants as having considered ovarian cancer surveillance if they responded that they had decided to have it, decided not to have it or thought about it but had not decided. We calculated the proportions of participants who met these criteria and the exact 95\% binomial confidence interval for these estimates.

We calculated descriptive statistics for demographic factors (e.g., age, race/ethnicity, education, insurance status), cancer family history, and calculated scores for cancer genetics knowledge, perceived cancer risk, and cancer-related worry, anxiety and distress.

Participants. recall of breast and ovarian cancer risk management recommendations made by their genetics team at results disclosure and by their physician(s) at any point after disclosure was compared with 2012 NCCN recommendations. For each cancer type, and for genetics team recommendations and physician recommendations, we developed dichotomous variables of concordance between recalled recommendations and NCCN recommendations (all/some recalled recommendations concordant vs. no recommendations concordant). All or some were combined to reduce the chances of small cell sizes for the bivariate models. We developed similar, dichotomous variables to summarize concordance between medical records-abstracted recommendations made by the genetics team at results disclosure and current NCCN recommendations. Bivariate and multivariable logistic regression models were used to assess associations between participant characteristics and adherence to risk management guidelines separately for breast cancer, ovarian cancer, and adherence for both cancers. For each adherence outcome, the final multivariable model was selected using backwards stepwise selection, starting with a model that included all variables significant at $\mathrm{p}<0.1$ in bivariate analysis. We used $\mathrm{p}$-value threshold higher than 0.05 for entry into the multivariable model to reduce the chance of excluding a potentially significant variable from 
the final model. We then removed non-significant variables one-at-a-time until only variables significant at $\mathrm{p}<0.05$ remained. $\mathrm{R}^{2}$ values (calculated using the Cox \& Snell method) and likelihood p-values comparing final and null models were calculated for the final multivariable models.

Data from the open-ended items were content-analyzed to identify common reasons for adherence and non-adherence. We used manifest content analysis (Hsieh \& Shannon, 2005), which is appropriate when relatively little is known about a phenomenon and the goal is to generate descriptive data for hypothesis generation. Two study investigators (AB and CV) coded the reported reasons for adherence and non-adherence together. Any initial disagreements in coding were resolved through discussion during the coding process. For each reason identified, we calculated a manifest frequency effect size (i.e., proportion of participants who listed that reason) (Onwuegbuzie, 2003). Reasons for adherence and nonadherence were ranked separately to elucidate prominent facilitators of and barriers to adherence, which then can be targeted in future interventions.

\section{RESULTS}

\section{Enrollment Summary}

As summarized in Figure 2, queries of clinic databases identified 178 potentially eligible individuals. Study staff were unable to reach 56 of these individuals by phone. Of those who were reached, six were found to be ineligible due to diagnosis of breast or ovarian cancer since results disclosure and twelve declined participation. Women who completed the survey were similar to those who did not complete the survey with respect to age, race and Hispanic ethnicity ( $\mathrm{p}>0.5$ for all three comparisons). However, women seen at Duke agreed to participate at a greater rate than those seen at UNC (63\% vs $47 \%, \mathrm{p}=0.04)$.

\section{Participant Characteristics}

Participant characteristics, shown in Table I, did not differ significantly by clinic.

Participants were largely Caucasian, married, employed, well-educated, well insured and had income higher than $\$ 50,000$. The majority of participants who were not Caucasian were African American. Median number of years since results disclosure was 3.7 among Duke participants and 4.5 among UNC participants. Median breast cancer genetics knowledge score was high ( 9 out of 10 in both clinics). Cancer-specific distress was 7.0 among Duke participants and 12.0 among UNC participants (scale range 0-75 - see Table 1). On average, participants reported communicating test results with $75 \%$ of their living first- and seconddegree relatives.

Nearly one third of participants $(31 \%)$ reported receiving conflicting risk management recommendations from different physicians after they received their genetic test results. Eighty percent of participants reported that their genetics team recommended breast cancer risk management that was concordant with some or all of the corresponding 2012 NCCN recommendations; $38 \%$ of participants reported that their genetics team made ovarian cancer risk management recommendations that were consistent with 2012 NCCN recommendations. Participants reported similar concordance between post-disclosure 
physician recommendations for breast and ovarian cancer risk management and the corresponding 2012 NCCN recommendations, with $76 \%$ concordance for some or all breast cancer risk management recommendations and $24 \%$ concordance for some or all ovarian cancer risk management recommendations. By medical records review, genetics team recommendations for breast cancer risk management were concordant with some or all of the corresponding 2012 NCCN recommendations for $88 \%$ of participants. Genetics team recommendations for ovarian cancer risk management were concordant with some or all of the corresponding $2012 \mathrm{NCCN}$ recommendations for $1 \%$ of participants.

\section{Adherence to Recommended Risk Management}

More than half of participants were adherent with risk management recommendations for breast cancer, ovarian cancer and both cancers (Table II). Adherence was highest among participants age 40 years and older, with rates of $75 \%$ or greater. Among participants adherent to recommended breast cancer risk management, $51 \%$ had bilateral mastectomies and $49 \%$ had both surveillance tests within the recommended time period. Among those adherent to recommended ovarian cancer risk management, $72 \%$ had bilateral oophorectomies and $28 \%$ had considered both surveillance tests.

\section{Factors Associated with Adherence}

In bivariate analyses that included all participant characteristics in Table I, white race, higher income, higher breast cancer genetics knowledge, and higher physical functioning were associated with greater adherence to breast cancer risk management (Table III). In multivariable analyses, white race $(\mathrm{OR}=4.80,95 \% \mathrm{CI}=1.21-19.06, \mathrm{p}=0.026)$ and higher knowledge $(\mathrm{OR}=1.61,95 \% \mathrm{CI}=1.10-2.34, \mathrm{p}=0.013)$ remained significantly associated with adherence $\left(\mathrm{R}^{2}=0.12, \mathrm{p}=0.0022\right)$.

Older age, higher income and higher physical functioning were associated with greater adherence to recommended ovarian cancer risk management in bivariate analyses (Table III). Older age $(\mathrm{OR}=7.25,95 \% \mathrm{CI}=1.36-38.46, \mathrm{p}=0.020$ for age $40+\mathrm{v}$. 30-39) and higher household income $(\mathrm{OR}=8.49,95 \% \mathrm{CI}=1.62-43.86, \mathrm{p}=0.011)$ remained significantly associated with adherence in the multivariable model $\left(\mathrm{R}^{2}=0.13, \mathrm{p}=0.0029\right)$.

In bivariate analyses, older age, white race, higher income, higher breast cancer genetics knowledge, higher cancer-specific distress, higher physical functioning, and greater concordance between current NCCN guidelines and participants. report of physicians. ovarian cancer risk management recommendations were associated with greater adherence to risk management for both cancers (Table III). Older age ( $\mathrm{OR}=4.76,95 \% \mathrm{CI}=1.02-22.22$, $\mathrm{p}=0.047$ for age $40+$ v. $25-29 ; \mathrm{OR}=10.53,95 \% \mathrm{CI}=2.56-43.48, \mathrm{p}=0.001$ for age $40+\mathrm{v} .30-$ $39)$, white race $(\mathrm{OR}=8.93,95 \% \mathrm{CI}=1.43-55.56, \mathrm{p}=0.019)$, higher knowledge $(\mathrm{OR}=1.67$, 95\% CI=1.05-2.65, $\mathrm{p}=0.030)$, higher cancer-specific distress $(\mathrm{OR}=1.07,95 \% \mathrm{CI}=1.03-1.12$, $\mathrm{p}=0.002)$ and higher physical functioning $(\mathrm{OR}=1.09,95 \% \mathrm{CI}=1.02-1.15, \mathrm{p}=0.009)$ remained significantly associated with adherence to recommended risk management for both cancers on multivariable analyses $\left(\mathrm{R}^{2}=0.32, \mathrm{p}<0.0001\right)$. 


\section{Reasons to Perform and Not Perform Recommended Behaviors}

The most commonly reported main reasons to have and not to have each risk management behavior are summarized in Tables IV and V. Because responses for prophylactic surgery tended to differ from those for surveillance, surgery and surveillance tables are presented separately. Participants reported risk reduction as the most common reason to perform prophylactic surgery (Table IV). The ability of surveillance tests to detect abnormalities and to do so early were the most commonly reported reasons to have surveillance (Table V). Some participants reported nuanced views of surveillance, including a recognition that breast MRI can be more sensitive that mammography but may be costly, and that there are clinical validity concerns with ovarian cancer surveillance (Table V). Of note, substantial proportions of participants (ranging from 10\% for prophylactic oophorectomy to 59\% for mammography) were unable to think of reasons not to perform prophylactic surgery and surveillance (Tables IV and V). The list of reasons not to have prophylactic surgery was short and, for prophylactic oophorectomy, was focused on wanting to maintain fertility and avoid menopausal symptoms (Table IV).

\section{DISCUSSION}

We found that adherence to $2012 \mathrm{NCCN}$ guidelines for cancer risk management among unaffected female $B R C A$ mutation carriers who underwent standard-of-care cancer genetic counseling at one of two NCI-designated comprehensive cancer centers exceeded 50\%, with adherence rates greater than $75 \%$ in women older than age 40 . Rates of prophylactic surgery reported in our study (prophylactic oophorectomy $=63 \%$, prophylactic mastectomy $=35 \%$ ) were consistent with rates in several similar studies (Bradbury et al., 2008; Friebel et al., 2007; Garcia et al., 2014; Schwartz et al., 2012). Our qualitative findings suggest that participants recognized prophylactic surgery and surveillance as effective methods for managing one's risk for breast and ovarian cancer. Several were unable to think of reasons not to perform risk management behaviors. Given that median time since test results disclosure was 3.7 years in the Duke clinic participants and 4.5 years in the UNC clinic participants, the relatively high self-reported adherence to all recommended management is encouraging, though it does leave room for improvement - and possible targets for interventions - among women under 40 and other sub-groups.

Several factors were significantly associated with adherence to recommended risk management for breast cancer, ovarian cancer and both cancers. Some of these findings can be readily applied to development of interventions to improve adherence, while others require further study or are less amenable to intervention. Consistent with several other reports of factors associated with risk-reducing surgery (Botkin et al., 2003; Bradbury et al., 2008; Friebel et al., 2007; Garcia et al., 2014; Julian-Reynier et al., 2010; O'Neill et al., 2010; Schmeler et al., 2006; Schwartz et al., 2012), older age was associated with greater adherence to recommended management for ovarian cancer and for both cancers together. Maintaining fertility and the ability to breastfeed were the most commonly reported reasons to not have prophylactic surgery. This finding echoes recent qualitative studies of risk management among unaffected women with HBOC syndrome, which have described the 
complex decision making involved in balancing fertility and breastfeeding with risk management (Caiata-Zufferey \& Pagani, 2015; Leonarczyk \& Mawn, 2015).

Higher breast cancer genetics knowledge was significantly associated with higher adherence to breast cancer risk management and to recommended management for both cancers. This suggests that a basic level of genetic literacy, specific to a condition, may be associated with greater adherence to recommended management for that condition. Perhaps the high knowledge in both clinic populations and association between knowledge and adherence are indications of effective genetic counseling, as others have found (Calzone et al., 2005; Hadley et al., 2004; Pal et al., 2014; Scheuer et al., 2002; Watson et al., 2005). Or, perhaps this particular population was already knowledgeable about HBOC genetics and risk management. A majority of participants (77\%) had single-site genetic testing, indicating that their families were already aware of a familial $B R C A$ mutation. If family communication about the mutation included basic genetics and risk management concepts, this communication could have been responsible for the high knowledge and adherence. Studies to determine the type and amount of information associated with adherence and mode for delivering this information (e.g., standard cancer genetic counseling, primary care physician discussion, family communication) are warranted.

Our finding that higher physical functioning was associated with greater adherence to recommended risk management for both cancers is intuitive, as poorer functioning makes it difficult to perform surveillance or undergo prophylactic surgery. Although we found that cancer-specific distress was associated with adherence to risk management for both cancers, it is notable that distress was in the intermediate range (median=12) among those adherent for both cancers, whereas distress for those non-adherent for both cancers was in the low range (median=4.5). This may be another example of the Yerkes-Dodson law (Yerkes \& Dodson, 1908), in which there is a "just right" amount of distress that spurs action but is not debilitating.

\section{Practice Implications}

Standard-of-care cancer genetic counseling is designed to facilitate some of the factors we found to be associated with adherence, including educating about the basic genetics of a hereditary cancer syndrome and improving risk perception while providing patients with achievable methods of managing their risks (American Society of Clinical Oncology, 2003; Berliner, Fay, Cummings, Burnett, \& Tillmanns, 2013; Berliner et al., 2007; Trepanier et al., 2004). What interventions might we suggest, then, that go beyond standard cancer genetic counseling to further support women who remain non-adherent?

Enlisting supportive resources (e.g., clinic social worker, online support groups) may help younger women who are not prepared to proceed with prophylactic surgery to remain adherent to surveillance recommendations. These supportive resources may need to be available long-term, given that decisions about risk management can remain complex as women pass through different life stages, creating what some women with HBOC syndrome have described as a "lifelong risk balance analysis" (Leonarczyk \& Mawn, 2015). Providing logistical support for those with poorer physical functioning may include collaborating with patient navigators, transportation to clinics for surveillance or better access to home health 
nursing post-prophylactic surgery. Finally, any intervention tailored to an individual's perceived barriers to adherence will need to be prepared to respond to a long list of barriers, as many of the reasons to not perform particular risk management behaviors were only mentioned by a few participants.

A longitudinal, multi-disciplinary hereditary cancer clinic could be the ideal setting for designing these informational, supportive and logistical interventions, and testing whether they improve adherence. Providing a single clinic at which women with HBOC syndrome could receive current, consistent information on risk management as guidelines change could mitigate disorientation reported by women who receive different recommendations from different clinicians (Caiata-Zufferey \& Pagani, 2015; Leonarczyk \& Mawn, 2015).

\section{Research Recommendations}

Among our findings that bear further study was the link between race and adherence to recommended risk management for breast cancer and for both cancers. It would be premature to draw major conclusions from our study given that there were only 11 minority participants. It is unlikely that race was a proxy for differential access to care in our study (Chagpar, Polk, \& McMasters, 2008; Miranda, Tarraf, \& Gonzalez, 2011) because nearly all participants $(89 \%)$ were insured and, by virtue of having had cancer genetic counseling, were already connected to a cancer center that could provide their risk management.

The association between higher income and adherence to ovarian cancer risk management is an apparently novel finding that merits further study. The majority of women who were adherent for ovarian cancer risk management did so by having prophylactic oophorectomy. Perhaps having higher income makes it easier to manage post-surgery challenges such as recovery time and menopausal symptoms.

Our study was notable for what we did not find. Our Health Belief Model-based theoretical framework and previous research suggested a list of variables that could be associated with adherence, but were not. These included insurance status, education, cancer worry, family history of breast or ovarian cancer (Bradbury et al., 2008; Friebel et al., 2007; Julian-Reynier et al., 2010), mental functioning and the concordance of patient recall of geneticistrecommended management with current management guidelines. Neither was time since results disclosure associated with adherence, which is surprising given that management guidelines have changed for at least one behavior in eight of the 15 years since risk management guidelines were first published in 1997 and the 2012 NCCN guidelines used for this study (Burke et al., 1997; NCCN, 2000, 2001, 2002, 2003, 2005, 2006, 2010, 2012). Surprising, too, was the finding that a substantial proportion of participants reported receiving conflicting risk management recommendations from different clinicians, but concordance between participants. recall of recommended behaviors and NCCN guidelines was not associated with adherence. Perhaps the lack of association between some of these characteristics and adherence is merely due to insufficient power. Larger studies of adherence may still include these characteristics. 


\section{Study Limitations and Strengths}

It is unclear how generalizable study findings are to community clinic settings or other regions. Data were drawn from two tertiary care institutions in close proximity to one another, with a significantly higher participation rate in the Duke clinic. And, although participants and non-participants did not differ significantly on age, race or Hispanic ethnicity, it is possible that they differed on factors that were not available in the clinic databases.

Among other study limitations is that the study was not designed to evaluate associations between specific perceived benefits of and barriers to adherence among those who were nonadherent. This is due in part to the decision to ask participants about perceived benefits and barriers generally, rather than about their own perceived benefits and barriers. Additionally, given the sample size and the fact that the list of perceived benefits and barriers for many of the behaviors was fairly long and individualized, it is unlikely that there would have been sufficient power to investigate these associations even if we had intended to. Future studies may wish to assess the link between perceived benefits and barriers and adherence to recommended risk management, as well as the association between the balance of an individual's perceived benefits of and barriers to risk management behaviors and adherence to recommended behaviors (O'Neill et al., 2010). Further, participants. self-report of risk management behaviors may be inaccurate. However, we are encouraged by previous reports of the validity of mammography self-report (Caplan et al., 2003; King et al., 1990; Rauscher, Johnson, Cho, \& Walk, 2008; Zapka et al., 1996) and the correlation of patient report of screening and physician recommendation via chart audit (Montano \& Phillips, 1995).

This study also has several strengths. It supplements previous literature by focusing on adherence to all recommended risk management behaviors among unaffected women, assessing characteristics associated with adherence in this population, and reporting qualitative data that add nuance to these associations. Additional strengths include a relatively long follow-up period during which management guidelines changed several times, the assessment of a broad range of variables potentially associated with adherence (including participants. recall of clinicians. management recommendations) and a theoretical framework to inform selection of these variables.

\section{Conclusions}

This study is among the first to provide an important snapshot of adherence to current recommended risk management among unaffected women with a BRCA mutation. We found that, in spite of a median of several years since results disclosure, a majority of participants were adherent with current management guidelines for unaffected women with a $B R C A$ mutation. Adherence was particularly high among women older than age 40. Younger individuals and those with lower physical functioning may require targeted interventions to improve adherence, perhaps in the setting of long-term follow-up at a multidisciplinary hereditary cancer clinic. To ensure that all individuals with HBOC syndrome have the opportunity to realize the associated beneficial health outcomes, we propose assessing risk management adherence in a larger, more racially and ethnically diverse sample. 


\section{Acknowledgments}

The authors are grateful to the women who participated in cognitive interviewing for the study.

\section{References}

American Society of Clinical Oncology. American Society of Clinical Oncology policy statement update: genetic testing for cancer susceptibility. J Clin Oncol. 2003; 21(12):2397-2406. DOI: 10.1200/jco.2003.03.189 [PubMed: 12692171]

Berliner JL, Fay AM, Cummings SA, Burnett B, Tillmanns T. NSGC practice guideline: risk assessment and genetic counseling for hereditary breast and ovarian cancer. J Genet Couns. 2013; 22(2):155-163. [PubMed: 23188549]

Berliner JL, Fay AM. Practice Issues Subcommittee of the National Society of Genetic Counselors' Familial Cancer Risk Counseling Special Interest G. Risk assessment and genetic counseling for hereditary breast and ovarian cancer: recommendations of the National Society of Genetic Counselors. J Genet Couns. 2007; 16(3):241-260. [PubMed: 17508274]

Botkin JR, Smith KR, Croyle RT, Baty BJ, Wylie JE, Dutson D, ... Lyon E. Genetic testing for a BRCA1 mutation: prophylactic surgery and screening behavior in women 2 years post testing. Am $\mathrm{J}$ Med Genet Part A. 2003; 118(3):201-209.

Bradbury AR, Ibe CN, Dignam JJ, Cummings SA, Verp M, White MA, ... Olopade OI. Uptake and timing of bilateral prophylactic salpingo-oophorectomy among BRCA1 and BRCA2 mutation carriers. Genet Med. 2008; 10(3):161-166. [PubMed: 18344704]

Buchanan AH, Skinner CE, Calingaert B, Schildkraut JM, King RH, Marcom PK. Cancer genetic counseling in rural North Carolina oncology clinics: program establishment and patient characteristics. Commun Oncol. 2009; (6):70-77.

Burke W, Daly M, Garber J, Botkin J, Kahn MJ, Lynch P, ... Varricchio C. Recommendations for follow-up care of individuals with an inherited predisposition to cancer. II. BRCA1 and BRCA2. Cancer Genetics Studies Consortium. JAMA. 1997; 277(12):997-1003. [PubMed: 9091675]

Caiata-Zufferey M, Pagani O. Challenges in managing genetic cancer risk: a long-term qualitative study of unaffected women carrying BRCA1/BRCA2 mutations. Genet Med. 2015; 17(9):726-732. DOI: 10.1038/gim.2014.183 [PubMed: 25503500]

Calzone KA, Prindiville SA, Jourkiv O, Jenkins J, DeCarvalho M, Wallerstedt DB, ... Kirsch IR. Randomized comparison of group versus individual genetic education and counseling for familial breast and/or ovarian cancer. J Clin Oncol. 2005; 23(15):3455-3464. [PubMed: 15908654]

Caplan LS, McQueen DV, Qualters JR, Leff M, Garrett C, Calonge N. Validity of women's self-reports of cancer screening test utilization in a managed care population. Cancer Epidemiol Biomarkers Prev. 2003; 12(11 Pt 1):1182-1187. [PubMed: 14652278]

CDC. Office of Public Health Genomics - Genomic Tests and Family History by Levels of Evidence. 2014 Sep 8. Retrieved April 28, 2015, from http://www.cdc.gov/genomics/gtesting/tier.htm

Chagpar AB, Polk HC Jr, McMasters KM. Racial trends in mammography rates: a population-based study. Surgery. 2008; 144(3):467-472. [PubMed: 18707047]

Chen S, Parmigiani G. Meta-analysis of BRCA1 and BRCA2 penetrance. J Clin Oncol. 2007; 25(11): 1329-1333. [PubMed: 17416853]

Claes E, Evers-Kiebooms G, Decruyenaere M, Denayer L, Boogaerts A, Philippe K, Legius E. Surveillance behavior and prophylactic surgery after predictive testing for hereditary breast/ ovarian cancer. Behav Med. 2005; 31(3):93-105. [PubMed: 16252621]

Finch A, Beiner M, Lubinski J, Lynch HT, Moller P, Rosen B, ... Narod SA. Salpingo-oophorectomy and the risk of ovarian, fallopian tube, and peritoneal cancers in women with a BRCA1 or BRCA2 Mutation. JAMA. 2006; 296(2):185-192. [PubMed: 16835424]

Finch AP, Lubinski J, Moller P, Singer CF, Karlan B, Senter L, ... Narod SA. Impact of oophorectomy on cancer incidence and mortality in women with a BRCA1 or BRCA2 mutation. J Clin Oncol. 2014; 32(15):1547-1553. [PubMed: 24567435]

Friebel TM, Domchek SM, Neuhausen SL, Wagner T, Evans DG, Isaacs C, ... Rebbeck TR. Bilateral prophylactic oophorectomy and bilateral prophylactic mastectomy in a prospective cohort of 
unaffected BRCA1 and BRCA2 mutation carriers. Clin Breast Cancer. 2007; 7(11):875-882. [PubMed: 18269778]

Garcia C, Wendt J, Lyon L, Jones J, Littell RD, Armstrong MA, ... Powell CB. Risk management options elected by women after testing positive for a BRCA mutation. Gynecol Oncol. 2014; 132(2):428-433. [PubMed: 24355485]

Hadley DW, Jenkins JF, Dimond E, de Carvalho M, Kirsch I, Palmer CG. Colon cancer screening practices after genetic counseling and testing for hereditary nonpolyposis colorectal cancer. J Clin Oncol. 2004; 22(1):39-44. [PubMed: 14701766]

Harris PA, Taylor R, Thielke R, Payne J, Gonzalez N, Conde JG. Research electronic data capture (REDCap)--a metadata-driven methodology and workflow process for providing translational research informatics support. J Biomed Inform. 2009; 42(2):377-381. [PubMed: 18929686]

Horowitz MJ, Wilner N, Alvarez W. Impact of Event Scale: A measure of subjective stress. Psychosom Med. 1979; 41(3):209-218. [PubMed: 472086]

Hsieh HF, Shannon SE. Three approaches to qualitative content analysis. Qual Health Res. 2005; 15(9):1277-1288. [PubMed: 16204405]

Hughes C, Lerman C, Schwartz M, Peshkin B, Wenzel L, Narod S, ... Isaacs C. All in the family: Evaluation of the processand content of sisters' communication about BRCA1 and BRCA2 genetic test results. Am J Med Genet. 2002; 107:143-150. [PubMed: 11807889]

Julian-Reynier C, Bouhnik AD, Mouret-Fourme E, Gauthier-Villars M, Berthet P, Lasset C, ... Nogues C. Time to prophylactic surgery in BRCA1/2 carriers depends on psychological and other characteristics. Genet Med. 2010; 12(12):801-807. [PubMed: 20921896]

Khoury MJ, Coates RJ, Evans JP. Evidence-based classification of recommendations on use of genomic tests in clinical practice: dealing with insufficient evidence. Genet Med. 2010; 12(11): 680-683. [PubMed: 20975567]

King ES, Rimer BK, Trock B, Balshem A, Engstrom P. How valid are mammography self-reports? Am J Public Health. 1990; 80(11):1386-1388. [PubMed: 2240315]

Kinney AY, Simonsen SE, Baty BJ, Mandal D, Neuhausen SL, Seggar K, ... Smith K. Risk reduction behaviors and provider communication following genetic counseling and BRCA1 mutation testing in an African American kindred. J Genet Couns. 2006; 15(4):293-305. [PubMed: 16865561]

Kurian AW, Sigal BM, Plevritis SK. Survival analysis of cancer risk reduction strategies for BRCA1/2 mutation carriers. J Clin Oncol. 2010; 28(2):222-231. [PubMed: 19996031]

Leonarczyk TJ, Mawn BE. Cancer risk management decision making for BRCA+ women. West J Nurs Res. 2015; 37(1):66-84. [PubMed: 24470135]

Lerman C, Hughes C, Croyle RT, Main D, Durham C, Snyder C, ... Lynch HT. Prophylactic surgery decisions and surveillance practices one year following BRCA1/2 testing. Prev Med. 2000; 31(1): 75-80. [PubMed: 10896846]

Lodder LN, Frets PG, Trijsburg RW, Meijers-Heijboer EJ, Klijn JG, Seynaeve C, ... Niermeijer MF. One year follow-up of women opting for presymptomatic testing for BRCA1 and BRCA2: emotional impact of the test outcome and decisions on risk management (surveillance or prophylactic surgery). Breast Cancer Res Treat. 2002; 73(2):97-112. [PubMed: 12088120]

Meijers-Heijboer EJ, Verhoog LC, Brekelmans CT, Seynaeve C, Tilanus-Linthorst MM, Wagner A, ... Klijn JG. Presymptomatic DNA testing and prophylactic surgery in families with a BRCA1 or BRCA2 mutation. Lancet. 2000; 355(9220):2015-2020. [PubMed: 10885351]

Meijers-Heijboer H, Brekelmans CT, Menke-Pluymers M, Seynaeve C, Baalbergen A, Burger C, ... Klijn JG. Use of genetic testing and prophylactic mastectomy and oophorectomy in women with breast or ovarian cancer from families with a BRCA1 or BRCA2 mutation. J Clin Oncol. 2003; 21(9):1675-1681. [PubMed: 12721241]

Metcalfe KA, Birenbaum-Carmeli D, Lubinski J, Gronwald J, Lynch H, Moller P. ... Hereditary Breast Cancer Clinical Study G. International variation in rates of uptake of preventive options in BRCA1 and BRCA2 mutation carriers. Int J Cancer. 2008; 122(9):2017-2022. [PubMed: 18196574]

Miranda PY, Tarraf W, Gonzalez HM. Breast cancer screening and ethnicity in the United States: implications for health disparities research. Breast Cancer Res Treat. 2011; 128(2):535-542. [PubMed: 21298477] 
Montano DE, Phillips WR. Cancer screening by primary care physicians: a comparison of rates obtained from physician self-report, patient survey, and chart audit. Am J Public Health. 1995; 85(6):795-800. [PubMed: 7762712]

NCCN. NCCN Practice Guidelines: Genetics/Familial High-Risk Cancer Screening. 2000 Jun 01. Retrieved February 11, 2011, from http://www.nccn.org/professionals/physician_gls/pdf/ genetics_screening.pdf

NCCN. Clinical Practice Guidelines in Oncology - Genetic/Familial High-Risk Screening: Breast Version 1.2001. 2001 Apr 19. Retrieved February 11, 2011, from http://www.ncen.org/ professionals/physician_gls/pdf/genetics_screening.pdf

NCCN. Clinical Practice Guidelines in Oncology - Genetic/Familial High-Risk Assessment: Breast Version 1.2002. 2002 Apr 22. Retrieved February 11, 2011, from http://www.nccn.org/ professionals/physician_gls/pdf/genetics_screening.pdf

NCCN. Clinical Practice Guidelines in Oncology - Genetic/Familial High-Risk Assessment: Breast and Ovarian Version 1.2003. 2003 Jul 28. Retrieved February, 2011, from http://www.nccn.org/ professionals/physician_gls/pdf/genetics_screening.pdf

NCCN. Clinical Practice Guidelines in Oncology - Genetic/Familial High-Risk Assessment: Breast and Ovarian Version 1.2005. 2005 Sep 09. Retrieved February 11, 2011, from http:// www.nccn.org/professionals/physician_gls/pdf/genetics_screening.pdf

NCCN. Clinical Practice Guidelines in Oncology - Genetic/Familial High-Risk Assessment: Breast and Ovarian Version 1.2006. 2006 Dec 14. Retrieved February 11, 2011, from http:// www.nccn.org/professionals/physician_gls/pdf/genetics_screening.pdf

NCCN. Clinical Practice Guidelines in Oncology - Genetic/Familial High-Risk Assessment: Breast and Ovarian Version 1.2010. 2010 Mar 08. Retrieved February 11, 2011, from http:// www.nccn.org/professionals/physician_gls/pdf/genetics_screening.pdf

NCCN. Clinical Practice Guidelines in Oncology - Genetic/Familial High-Risk Assessment: Breast and Ovarian Version 1.2012. 2012 May 02. Retrieved August 16, 2012, from http://www.nccn.org/ professionals/physician_gls/pdf/genetics_screening.pdf

NCCN. Clinical Practice Guidelines in Oncology - Genetic/Familial High-Risk Assessment: Breast and Ovarian Version 1.2015. 2015 Mar 30. Retrieved April 30, 2015, from http://www.nccn.org/ professionals/physician_gls/pdf/genetics_screening.pdf

O’Neill SC, Valdimarsdottir HB, Demarco TA, Peshkin BN, Graves KD, Brown K, ... Schwartz MD. BRCA1/2 test results impact risk management attitudes, intentions, and uptake. Breast Cancer Res Treat. 2010; 124(3):755-764. [PubMed: 20383578]

Onwuegbuzie A. Effect Sizes in Qualitative Research: A Prolegomenon. Quality \& Quantity. 2003; 37(4):393-409.

Pal T, Lee JH, Besharat A, Thompson Z, Monteiro AN, Phelan C, ... Narod SA. Modes of delivery of genetic testing services and the uptake of cancer risk management strategies in BRCA1 and BRCA2 carriers. Clin Genet. 2014; 85(1):49-53. [PubMed: 23438721]

Patenaude AF, Dorval M, DiGianni LS, Schneider KA, Chittenden A, Garber JE. Sharing BRCA1/2 test results with first-degree relatives: factors predicting who women tell. J Clin Oncol. 2006; 24(4):700-706. [PubMed: 16446344]

Peshkin BN, Schwartz MD, Isaacs C, Hughes C, Main D, Lerman C. Utilization of breast cancer screening in a clinically based sample of women after BRCA1/2 testing. Cancer Epidemiol Biomarkers Prev. 2002; 11(10 Pt 1):1115-1118. [PubMed: 12376518]

Petrucelli, N., Daly, MB., Feldman, GL. BRCA1 and BRCA2 Hereditary Breast and Ovarian Cancer. In: Pagon, RA.Adam, MP.Ardinger, HH.Wallace, SE.Amemiya, A.Bean, LJH.Bird, TD.Fong, CT.Smith, RJH., Stephens, K., editors. GeneReviews(R). Seattle (WA): University of Washington, Seattle University of Washington, Seattle; 2013. All rights reserved

Phillips KA, Jenkins MA, Lindeman GJ, McLachlan SA, McKinley JM, Weideman PC, ... kConFab I. Risk-reducing surgery, screening and chemoprevention practices of BRCA1 and BRCA2 mutation carriers: a prospective cohort study. Clin Genet. 2006; 70(3):198-206. [PubMed: 16922722]

Rauscher GH, Johnson TP, Cho YI, Walk JA. Accuracy of self-reported cancer-screening histories: a meta-analysis. Cancer Epidemiol Biomarkers Prev. 2008; 17(4):748-757. [PubMed: 18381468] 
Rebbeck TR, Friebel T, Lynch HT, Neuhausen SL, van 't Veer L, Garber JE, ... Weber BL. Bilateral prophylactic mastectomy reduces breast cancer risk in BRCA1 and BRCA2 mutation carriers: the PROSE Study Group. J Clin Oncol. 2004; 22(6):1055-1062. [PubMed: 14981104]

Rebbeck TR, Kauff ND, Domchek SM. Meta-analysis of risk reduction estimates associated with riskreducing salpingo-oophorectomy in BRCA1 or BRCA2 mutation carriers. J Natl Cancer Inst. 2009; 101(2):80-87. [PubMed: 19141781]

Riley BD, Culver JO, Skrzynia C, Senter LA, Peters JA, Costalas JW, ... Trepanier AM. Essential elements of genetic cancer risk assessment, counseling, and testing: updated recommendations of the National Society of Genetic Counselors. J Genet Couns. 2012; 21(2):151-161. [PubMed: 22134580]

Robson ME, Storm CD, Weitzel J, Wollins DS, Offit K. American Society of Clinical Oncology. American Society of Clinical Oncology policy statement update: genetic and genomic testing for cancer susceptibility. J Clin Oncol. 2009; 28(5):893-901.

Scheuer L, Kauff N, Robson M, Kelly B, Barakat R, Satagopan J, ... Offit K. Outcome of preventive surgery and screening for breast and ovarian cancer in BRCA mutation carriers. J Clin Oncol. 2002; 20(5):1260-1268. [PubMed: 11870168]

Schmeler KM, Sun CC, Bodurka DC, White KG, Soliman PT, Uyei AR, ... Lu KH. Prophylactic bilateral salpingo-oophorectomy compared with surveillance in women with BRCA mutations. Obstet Gynecol. 2006; 108(3 Pt 1):515-520. [PubMed: 16946209]

Schwartz MD, Isaacs C, Graves KD, Poggi E, Peshkin BN, Gell C, ... Perley L. Long-term outcomes of BRCA1/BRCA2 testing: risk reduction and surveillance. Cancer. 2012; 118(2):510-517. [PubMed: 21717445]

Schwartz MD, Kaufman E, Peshkin BN, Isaacs C, Hughes C, DeMarco T, ... Lerman C. Bilateral prophylactic oophorectomy and ovarian cancer screening following BRCA1/BRCA2 mutation testing. J Clin Oncol. 2003; 21(21):4034-4041. [PubMed: 14581427]

Schwartz MD, Lerman C, Brogan B, Peshkin BN, Halbert CH, DeMarco T, ... Isaacs C. Impact of BRCA1/BRCA2 counseling and testing on newly diagnosed breast cancer patients. J Clin Oncol. 2004; 22(10):1823-1829. [PubMed: 15067026]

Sidon L, Ingham S, Clancy T, Clayton R, Clarke A, Jones EA, ... Evans DG. Uptake of risk-reducing salpingo-oophorectomy in women carrying a BRCA1 or BRCA2 mutation: evidence for lower uptake in women affected by breast cancer and older women. Br J Cancer. 2012; 106(4):775-779. [PubMed: 22187038]

Skinner C, Rawl S, Moser B, Buchanan A, Scott L, Champion V, ... Bastian L. Impact of the Cancer Risk Intake System on patient-clinician discussions of tamoxifen, genetic counseling, and colonoscopy. J Gen Intern Med. 2005; 20(4):360-365. [PubMed: 15857495]

Skinner CS, Buchanan A, Champion V, Monahan P, Rawl S, Springston J, ... Bourff S. Process outcomes from a randomized controlled trial comparing tailored mammography interventions delivered via telephone vs. DVD. Patient Educ Couns. 2011; 85(2):308-312. [PubMed: 21112173]

Skinner, CS., Tiro, J., Champion, VL. The Health Belief Model. In: Glanz, K.Rimer, BK., Viswanath, K., editors. Health Behavior Theory, Research, and Practice. 5. San Francisco, CA: Jossey-Bass; 2015. p. 75-94.

Spielberger, CD., Gorsuch, R., Lushene, R., et al. State-Trait Anxiety Inventory for Adults: Sampler Set - Manual, Test, Scoring Key. Palo Alto, CA: Mind Garden; 1983.

Tinley ST, Houfek J, Watson P, Wenzel L, Clark MB, Coughlin S, Lynch HT. Screening adherence in BRCA1/2 families is associated with primary physicians' behavior. Am J Med Genet A. 2004; 125A(1):5-11. [PubMed: 14755459]

Trepanier A, Ahrens M, McKinnon W, Peters J, Stopfer J, Grumet SC. ... National Society of Genetic C. Genetic cancer risk assessment and counseling: recommendations of the National Society of Genetic Counselors. J Genet Couns. 2004; 13(2):83-114. [PubMed: 15604628]

Uyei A, Peterson SK, Erlichman J, Broglio K, Yekell S, Schmeler K, ... Arun B. Association between clinical characteristics and risk-reduction interventions in women who underwent BRCA1 and BRCA2 testing: a single-institution study. Cancer. 2006; 107(12):2745-2751. [PubMed: 17109443] 
Ware J Jr, Kosinski M, Keller SD. A 12-Item Short-Form Health Survey: construction of scales and preliminary tests of reliability and validity. Med Care. 1996; 34(3):220-233. [PubMed: 8628042]

Warner E, Hill K, Causer P, Plewes D, Jong R, Yaffe M, ... Narod SA. Prospective study of breast cancer incidence in women with a BRCA1 or BRCA2 mutation under surveillance with and without magnetic resonance imaging. J Clin Oncol. 2011; 29(13):1664-1669. [PubMed: 21444874]

Watson M, Kash KM, Homewood J, Ebbs S, Murday V, Eeles R. Does genetic counseling have any impact on management of breast cancer risk? Genet Test. 2005; 9(2):167-174. [PubMed: 15943558]

Willis, GB. Cognitive Interviewing. Thousand Oaks, CA: SAGE Publications; 2005.

Yerkes RM, Dodson JD. The relation of strength of stimulus to rapidity of habit-formation. Journal of Comparative Neurology and Psychology. 1908; 18:459-482.

Zapka JG, Bigelow C, Hurley T, Ford LD, Egelhofer J, Cloud WM, Sachsse E. Mammography use among sociodemographically diverse women: the accuracy of self-report. Am J Public Health. 1996; 86(7):1016-1021. [PubMed: 8669504] 


\begin{tabular}{|l|}
\hline \multicolumn{1}{|c|}{ Modifying Factors } \\
\hline Demographics \\
Age \\
Education \\
Race/ethnicity \\
Income \\
Insurance status \\
\hline \hline Psychological variables \\
Anxiety (SAI) \\
Cancer-specific distress (IES) \\
Cancer worry \\
Knowledge \\
\hline Physical/social health \\
Physical/social \\
functioning (SF-12) \\
\hline
\end{tabular}

\begin{tabular}{|c|c|}
\hline \multicolumn{2}{|c|}{$\underline{\text { Individual Beliefs }}$} \\
\hline $\begin{array}{l}\text { Perceived } \\
\text { cancer risk \& } \\
\text { severity }\end{array}$ & $\begin{array}{l}\text { Perceived } \\
\text { cancer } \\
\text { threat }\end{array}$ \\
\hline $\begin{array}{l}\text { Perceived } \\
\text { benefits (e.g., } \\
\text { risk reduction) }\end{array}$ & \\
\hline $\begin{array}{l}\text { Perceived } \\
\text { barriers (e.g., } \\
\text { cost, pain, } \\
\text { time) }\end{array}$ & \\
\hline $\begin{array}{l}\text { Perceived self- }- \\
\text { perform risk } \mathrm{m}\end{array}$ & $\begin{array}{l}\text { acy to } \\
\text { gement }\end{array}$ \\
\hline
\end{tabular}

\begin{tabular}{|l|}
\hline \multicolumn{1}{|c|}{ Action } \\
\hline $\begin{array}{l}\text { OuTCOMES } \\
\text { Prophylactic surgery } \\
\text { adoption } \\
\text { Surveillance } \\
\text { adoption }\end{array}$ \\
\hline \multicolumn{1}{|c|}{$\mid$} \\
\hline $\begin{array}{l}\text { Cues to Action } \\
\text { Cancer family } \\
\text { history } \\
\text { Physician risk } \\
\text { management } \\
\text { recommendation }\end{array}$ \\
\hline
\end{tabular}

Figure 1.

Theoretical Framework 


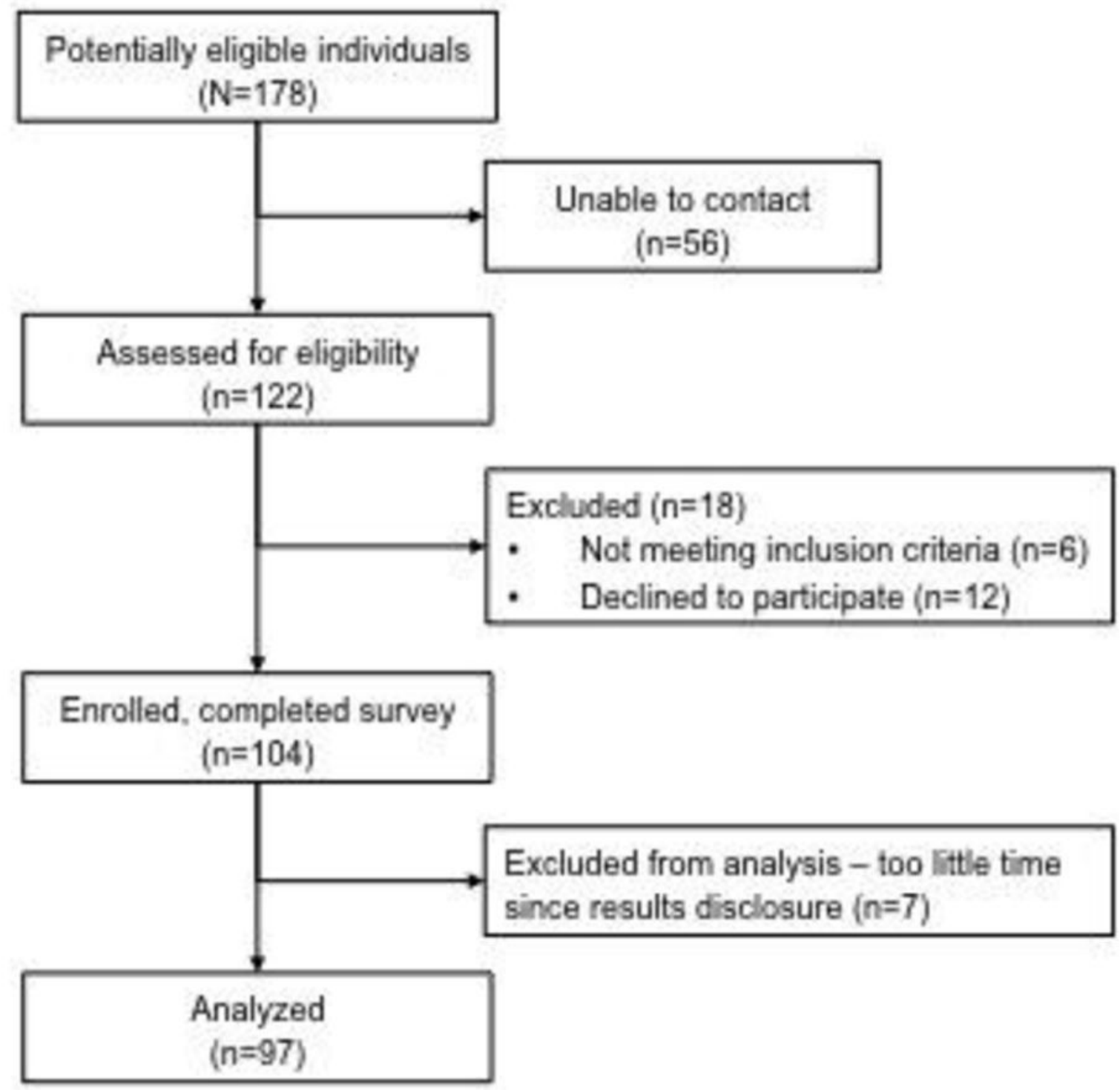

Figure 2.

Flowchart of recruitment and analysis 


\section{Table I}

Participant characteristics by clinic

\begin{tabular}{|c|c|c|c|}
\hline Characteristics & $\begin{array}{l}\text { Duke } \\
\text { n }(\%)\end{array}$ & $\begin{array}{l}\text { UNC } \\
\text { n (\%) }\end{array}$ & $\begin{array}{c}\text { Fisher's Exact Statistic Chi- } \\
\text { square (p-value) }\end{array}$ \\
\hline Age & & & $0.93(0.68)$ \\
\hline $25-29$ years & $6(12.0)$ & $7(14.9)$ & \\
\hline $30-39$ years & $16(32.0)$ & $11(23.4)$ & \\
\hline $40+$ years & $28(56.0)$ & $29(61.7)$ & \\
\hline Race & & & $2.93(0.11)$ \\
\hline Non-White & $3(6.0)$ & $8(17.0)$ & \\
\hline White & $47(94.0)$ & $39(83.0)$ & \\
\hline Hispanic ethnicity & $2(4.0)$ & $3(6.4)$ & $0.28(0.67)$ \\
\hline Married/living as married & $41(82.0)$ & $36(78.3)$ & $0.21(0.80)$ \\
\hline Employed & $37(74.0)$ & $30(66.7)$ & $0.61(0.50)$ \\
\hline Education level & & & $0.42(0.53)$ \\
\hline Less than college graduate & $18(36.0)$ & $14(29.8)$ & \\
\hline College graduate & $32(64.0)$ & $33(70.2)$ & \\
\hline Insurance status & & & $3.06(0.11)$ \\
\hline No private insurance & $3(6.0)$ & $8(17.4)$ & \\
\hline Private & $47(94.0)$ & $38(82.6)$ & \\
\hline Household income & & & $0.70(0.48)$ \\
\hline$\$ \$ 50,000$ & $10(20.8)$ & $13(28.3)$ & \\
\hline$\$ 50,001$ and above & $38(79.2)$ & $33(71.7)$ & \\
\hline Mutated gene & & & $0.87(0.42)$ \\
\hline BRCA1 & $24(48.0)$ & $27(57.5)$ & \\
\hline BRCA2 & $26(52.0)$ & $20(42.6)$ & \\
\hline Continuous variables (scale range) & Median (Range, SD) & Median (Range, SD) & Wilcoxon test p-value \\
\hline Years since results disclosure & $3.7(1.0-13.4,2.8)$ & $4.5(1.1-12.9,2.7)$ & 0.23 \\
\hline Knowledge (0-10) & $9.0(6.0-10.0,1.0)$ & $9.0(5.0-10.0,1.4)$ & 0.051 \\
\hline Breast cancer worry (3-9) & $4.0(3.0-8.0,1.6)$ & $3.0(3.0-9.0,1.5)$ & 0.40 \\
\hline Ovarian cancer worry (3-9) & $3.0(3.0-8.0,1.3)$ & $3.0(3.0-9.0,1.3)$ & 0.25 \\
\hline Anxiety (20-80) & $28.0(20.0-68.0,8.7)$ & $27.0(20.0-65.0,10.7)$ & 0.61 \\
\hline Cancer-specific distress (0-75) & $7.0(0.0-59.0,16.1)$ & $12.0(0.0-47.0,15.2)$ & 0.39 \\
\hline Physical functioning (0-100) & $55.2(19.5-62.4,7.3)$ & $54.8(19.7-66.0,11.6)$ & 0.62 \\
\hline
\end{tabular}

J Genet Couns. Author manuscript; available in PMC 2018 February 01. 


\begin{tabular}{|l|c|c|c|}
\hline Characteristics & $\begin{array}{c}\text { Duke } \\
\mathbf{n}(\%)\end{array}$ & $\begin{array}{c}\text { UNC } \\
\mathbf{n}(\%)\end{array}$ & $\begin{array}{c}\text { Fisher's Exact Statistic Chi- } \\
\text { square (p-value) }\end{array}$ \\
\hline Social functioning (0-100) & $54.6(31.8-62.7,6.7)$ & $54.1(27.9-62.4,9.3)$ & 0.42 \\
\hline $\begin{array}{l}\text { \# relatives with breast cancer } \\
\text { \# relatives with ovarian cancer }\end{array}$ & $3.0(0.0-12.0,2.4)$ & $4.0(0.0-19.0,3.7)$ & 0.20 \\
\hline $\begin{array}{l}\text { Proportion of relatives with whom results shared }(0- \\
\text { 100) }\end{array}$ & $75.1(27.3-100.0,20.7)$ & $79.2(11.1-100.0,20.2)$ & 0.68 \\
\hline
\end{tabular}


Table II

Adherence to recommend risk management, by cancer type and overall

\begin{tabular}{|c|c|c|c|}
\hline & \multicolumn{3}{|c|}{ Adherent, $\mathbf{n}(\%, 95 \%$ confidence interval for $\%)$} \\
\hline & $25-29 y^{*}$ & $30-39 y$ & $40+y$ \\
\hline Breast cancer risk management & $7(53.9,25.0-80.8)$ & $17(63.0,42.4-80.6)$ & $43(75.4,62.4-85.9)$ \\
\hline Ovarian cancer risk management & N/A & $21(77.8,57.7-91.4)$ & $53(93.0,83.0-98.1)$ \\
\hline Risk management - both cancers & $7(53.9,25.0-80.8)$ & $14(51.9,32.0-71.3)$ & $43(75.4,62.2-85.9)$ \\
\hline
\end{tabular}




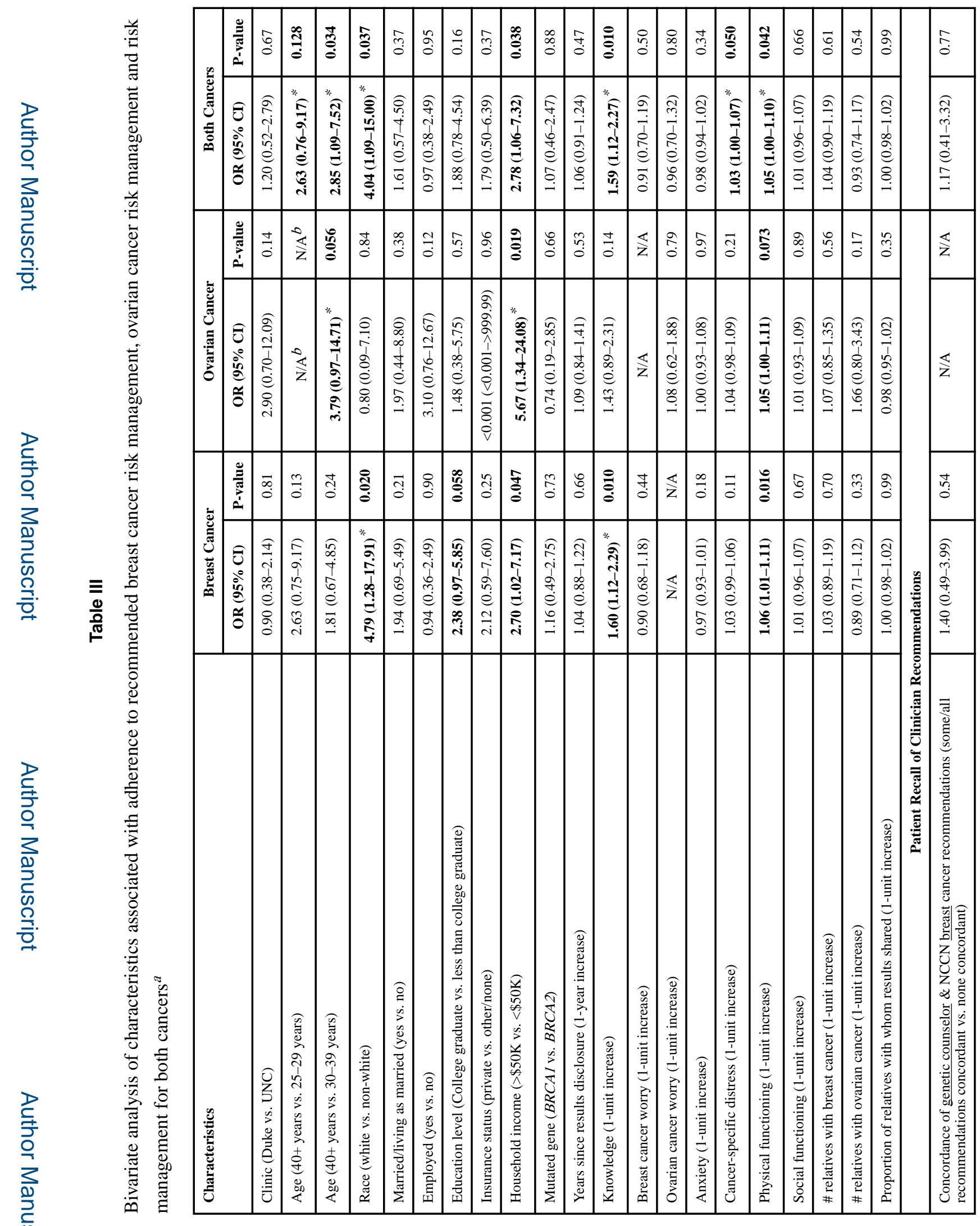

J Genet Couns. Author manuscript; available in PMC 2018 February 01. 


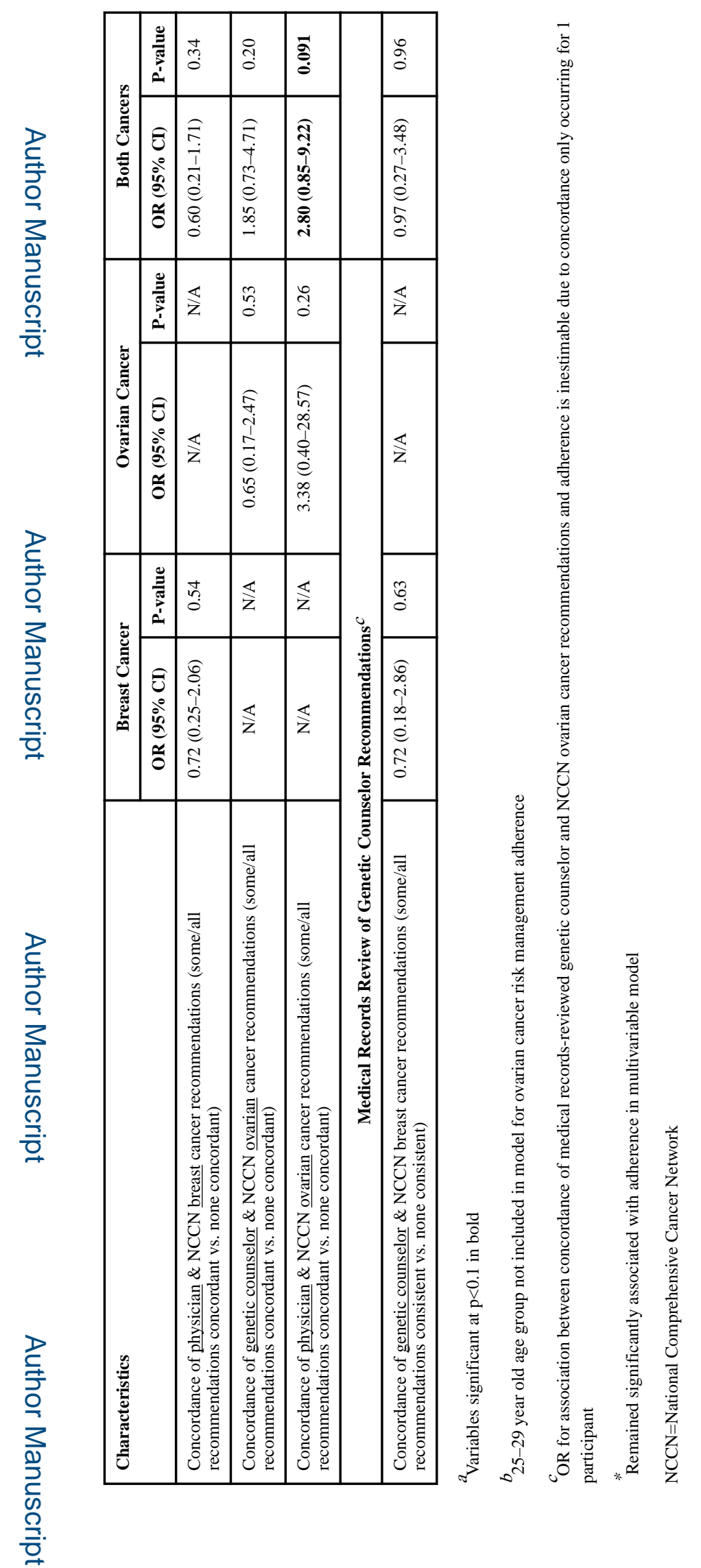

J Genet Couns. Author manuscript; available in PMC 2018 February 01. 
Table IV

Primary reasons to have and not to have prophylactic surgery mentioned by $\geq 10 \%$ of participants $(\mathrm{n}=97)$

\begin{tabular}{|l|c|c|}
\hline \multicolumn{1}{|c|}{ Reasons TO have surgery } & $\begin{array}{c}\text { Mastectomy } \\
\mathbf{n}(\%)\end{array}$ & $\begin{array}{c}\text { Oophorectomy } \\
\mathbf{n}(\%)\end{array}$ \\
\hline Reduce risk & $54(56 \%)$ & $67(69 \%)$ \\
\hline Treatment & $23(24 \%)$ & $<10 \%$ \\
\hline Peace of mind & $18(19 \%)$ & $<10 \%$ \\
\hline Completed childbearing & $<10 \%$ & $17(18 \%)$ \\
\hline Genetic risk & 0 & $14(14 \%)$ \\
\hline No good screening test & 0 & $14(14 \%)$ \\
\hline Reduce estrogen & 0 & $11(11 \%)$ \\
\hline Symptom management & $<10 \%$ & $10(10 \%)$ \\
\hline \multicolumn{1}{|c|}{ Reasons NOT to have surgery } & \multicolumn{2}{|c|}{} \\
\hline No reason not to & $20(21 \%)$ & $10(10 \%)$ \\
\hline Have not completed childbearing/breastfeeding & $16(16 \%)$ & $52(54 \%)$ \\
\hline Surgical complexity/complications & $11(11 \%)$ & 0 \\
\hline Might not get cancer & $10(10 \%)$ & 0 \\
\hline Side effects of menopause & 0 & $30(31 \%)$ \\
\hline
\end{tabular}




\section{Table V}

Primary reasons to and not to have surveillance mentioned by $\geq 10 \%$ of participants ( $\mathrm{n}=63$ for breast cancer surveillance; $\mathrm{n}=44$ for ovarian cancer surveillance)

\begin{tabular}{|l|c|c|c|c|}
\hline & $\begin{array}{c}\text { Mammogram } \\
\mathbf{n}(\mathbf{\%})\end{array}$ & $\begin{array}{c}\text { Breast MRI } \\
\mathbf{n}(\mathbf{\%})\end{array}$ & $\begin{array}{c}\text { CA-125 testing } \\
\mathbf{n}(\mathbf{\%})\end{array}$ & $\begin{array}{c}\text { Pelvic ultrasound } \\
\mathbf{n}(\mathbf{\%})\end{array}$ \\
\hline \multicolumn{1}{|c|}{ Reasons TO have surveillance } & \multicolumn{5}{|l|}{} \\
\hline Early detection & $30(48 \%)$ & $24(38 \%)$ & $16(36 \%)$ & $13(30 \%)$ \\
\hline Detect abnormality & $27(43 \%)$ & $10(16 \%)$ & $17(39 \%)$ & $29(66 \%)$ \\
\hline Better than alternative procedure & $<10 \%$ & $27(43 \%)$ & 0 & 0 \\
\hline Physician recommendation & $<10 \%$ & $13(21 \%)$ & $<10 \%$ & $<10 \%$ \\
\hline Symptom follow-up & $<10 \%$ & $9(14 \%)$ & $<10 \%$ & $<10 \%$ \\
\hline Two tests are better than one & 0 & $7(11 \%)$ & $<10 \%$ & $<10 \%$ \\
\hline Reasons NOT to have surveillance & & & & $21(48 \%)$ \\
\hline No reason not to & $37(59 \%)$ & $26(41 \%)$ & $14(32 \%)$ & 0 \\
\hline Radiation exposure & $10(16 \%)$ & $<10 \%$ & 0 & $<10 \%$ \\
\hline Age (too young or too old) & $10(16 \%)$ & $<10 \%$ & $<10 \%$ & $<10 \%$ \\
\hline Alternative procedure available & $9(14 \%)$ & $<10 \%$ & 0 & 0 \\
\hline Dense breasts & $8(13 \%)$ & $<10 \%$ & 0 & $10(23 \%)$ \\
\hline Cost & $<10 \%$ & $20(32 \%)$ & $6(14 \%)$ & $<10 \%$ \\
\hline Insurance status & $<10 \%$ & $7(11 \%)$ & $<10 \%$ & $<10 \%$ \\
\hline Clinical validity & $<10 \%$ & $<10 \%$ & $14(32 \%)$ & \\
\hline
\end{tabular}

